\title{
Expression of active yeast pyruvate decarboxylase in Escherichia coli
}

\author{
Judith M. Candy, ${ }^{1,2}$ Ronald G. DugGleby, ${ }^{2}$ and John S. Mattick ${ }^{1,2 *}$ \\ ${ }^{1}$ Centre for Molecular Biology and Biotechnology and ${ }^{2}$ Department of Biochemistry, The University of Queensland, \\ Brisbane QLD 4072, Australia
}

(Received 17 June 1991; revised 7 August 1991; accepted 5 September 1991)

\begin{abstract}
We have shown by appropriate modification of the translational signals and using the strong T7 RNA polymerase promoter $\phi 10$, that a cloned Saccharomyces cerevisiae pyruvate decarboxylase gene ( $p d c 1)$ can be expressed in Escherichia coli. This protein, which migrated as a single band on SDS-polyacrylamide gels, was found to have a subunit molecular mass of approximately $62 \mathrm{kDa}$, similar to that of the enzyme produced by yeast. Polyclonal antibodies raised against purified yeast pyruvate decarboxylase recognized this bacterially produced protein. We found that this recombinant enzyme is active, indicating that the homotetramer encoded by the pdc1 gene is functional.
\end{abstract}

\section{Introduction}

Pyruvate decarboxylase (PDC; EC 4.1.1.1) is a key enzyme in alcoholic fermentation, cleaving pyruvate to acetaldehyde and $\mathrm{CO}_{2}$. Both thiamine diphosphate (ThDP) and $\mathrm{Mg}^{2+}$ are essential cofactors and the enzyme is only active as a tetramer. In Saccharomyces cerevisiae, the tetramer may be composed of identical or nearly identical subunits (Gounaris et al., 1975; Zehender \& Ullrich, 1985; Kuo et al., 1986) but there is controversy as to their origin. The smaller $\beta$ chain was originally suggested to be the result of proteolytic cleavage of the $\alpha$ chain. However, Zehender \& Ullrich (1985) proposed that there were sufficient differences in the amino acid composition of the two chains to preclude this possibility. Kuo and co-workers (1986) isolated both $\alpha_{4}$ and $\alpha_{2} \beta_{2}$ enzyme forms from brewing yeast, each of which is active.

One way to confirm that the homomeric form of PDC is active is to express the enzyme from a cloned gene in a heterologous host. Moreover, if successful, the same system could then be used to study structure-function relationships of this protein. However, we found that the natural yeast $p d c l$ gene is not expressed well in Escherichia coli, presumably because it lacks suitable transcriptional and translational signals. Here we show that appropriate modification of those signals will give

Abbreviations: ECL, enhanced chemiluminescence; PDC, pyruvate decarboxylase; TBS, Tris-buffered saline; ThDP, thiamin diphosphate. high levels of expression in E. coli, and that the enzyme is active in this host.

\section{Methods}

Materials. Restriction enzymes and ligases were purchased from New England Biolabs or Toyobo and used according to the manufacturers' instructions. Nitrocellulose membranes (Hybond CExtra), the Enhanced Chemiluminescence (ECL) Kit, and radionucleotides were purchased from Amersham, and commercial yeast PDC (P-5651) from Sigma. Oligonucleotides were synthesized on a Milligen 7500 DNA synthesizer, and were used without further purification.

Strains and plasmids. The T7 RNA polymerase/promoter expression system, consisting of plasmids pGPI-2 (which contains the phage T7 gene 1 for RNA polymerase under the control of $\lambda \mathrm{P}_{\mathrm{L}}$ and $c$ I857) and p T7-7 (which contains the T7 $\phi$ promoter and the strong ribosome binding site from the $\mathrm{T} 7$ gene 10 protein inserted upstream of a multiple cloning site), was kindly supplied by S. Tabor (Harvard Medical School, USA) (Tabor \& Richardson, 1985). pGP1-2 was supplied already transformed into $E$. coli $\mathrm{K} 38(\mathrm{HfrCl})$. E. coli $\mathrm{DH} 5 \alpha\left[\mathrm{F}^{-} \phi 80 \mathrm{~d}\right.$ lacZ $\triangle \mathrm{M} 15$ endAl recAl hsdRI7 $\left(\mathrm{r}_{\mathrm{K}}, \mathrm{m}_{\mathrm{K}}^{+}\right)$supE44 thi-l $\lambda$ - gyrA96 $\triangle($ lac ZYA-argF) U169] was used for transformation and plasmid preparation. YEpl3-PDC1 (Schmitt et al., 1983) was kindly supplied by S. Hohmann (Institut fur Mikrobiologie, Technische Hochschule, Darmstadt, FRG). All strains were grown on Luria broth plates with appropriate antibiotics. Ampicillin and kanamycin were used at $75 \mu \mathrm{g} \mathrm{ml}^{-1}$. Cell growth was at $37^{\circ} \mathrm{C}$ except for $E$. coli containing pGP1-2 which was grown at $30^{\circ} \mathrm{C}$.

Plasmid construction. Standard methods were employed for plasmid and M13 bacteriophage preparation, restriction enzyme digestion, ligation and transformation (Maniatis et al., 1982). Plasmid constructions (Fig. 1) were transformed into E. coli DH5 $\alpha$.

Protein expression in E. coli. The following protocol was modified from that described by Tabor \& Richardson (1985). For expression of 
(a)

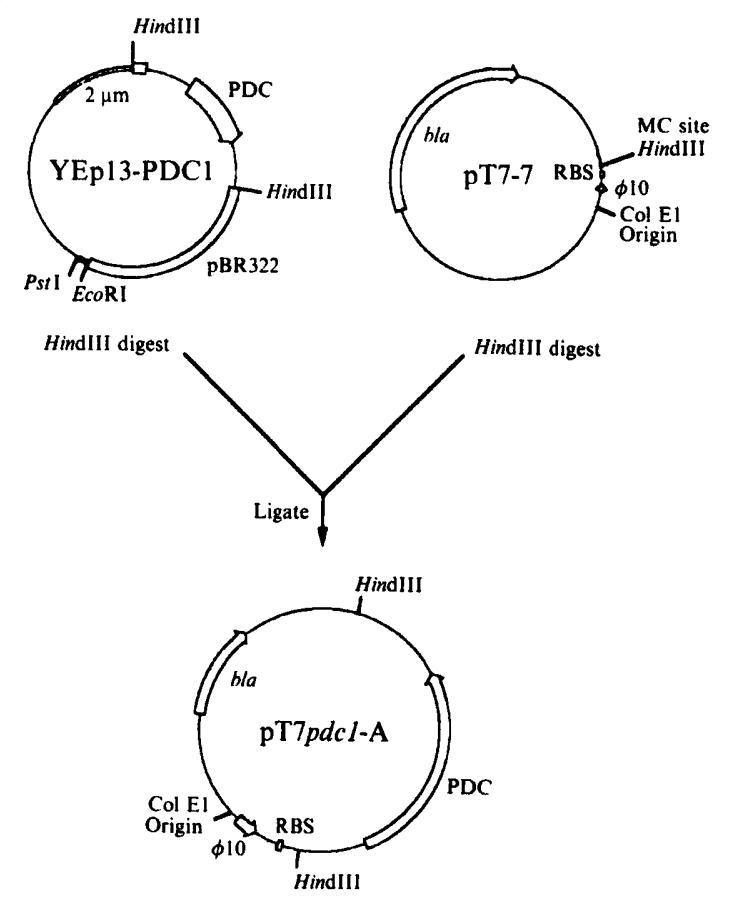

(b)
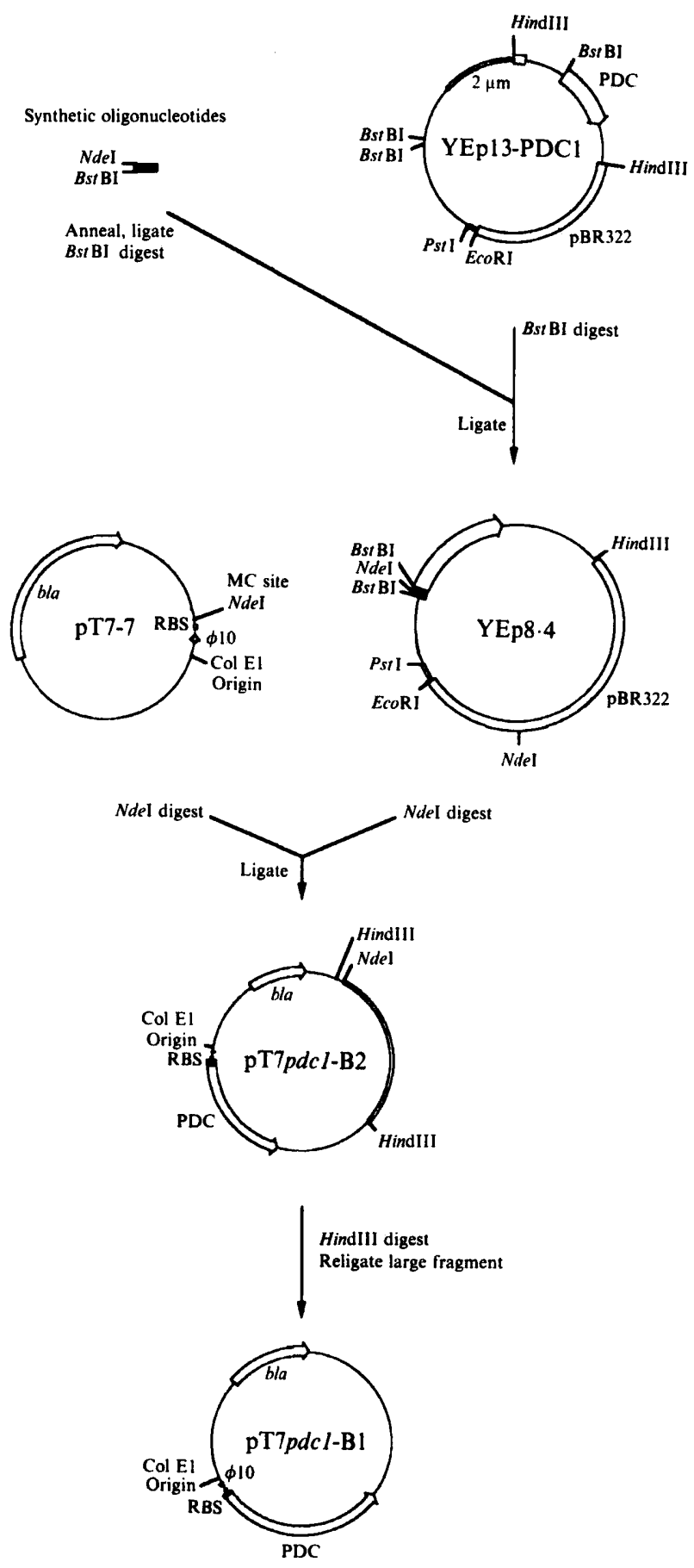

(c)

\section{5' TTTAAGAAGGAGATATACA TATGTCTGAAATTACTTTGGGTAAATATTTGTT 3' \\ RBS Synthetic oligonucleotide}

Fig. 1. Construction of plasmids pT7pdcl-A (a), pT7pdcl-B1 (b) and the nucleotide sequence of the $5^{\prime}$ region of the pdcl gene in pT7pdcl-B1 (c). The ribosome-binding site (RBS) and the synthetic oligonucleotide sequence are underlined. MC site, multiple cloning site. 
PDC in E. coli, derivatives of the plasmid pT7-7 were transformed into E. coli $\mathrm{K} 38$ containing pGP1-2. These cells were grown in $\mathrm{T} 7$ enrichment broth $(2 \%, \mathrm{w} / \mathrm{v}$, bacto-tryptone, $1 \%$, w/v, yeast extract, $0.5 \% \mathrm{NaCl}, 0.2 \%$ glycerol, $50 \mathrm{~mm}$-potassium phosphate, $\mathrm{pH} 7 \cdot 2)$ under ampicillin and kanamycin selection. Cells were grown at $30^{\circ} \mathrm{C}$ to an $\mathrm{OD}_{590}$ of $1 \cdot 5$, then heated to $42^{\circ} \mathrm{C}$ for $30 \mathrm{~min}$ to induce the synthesis of T7 RNA polymerase. The temperature was then lowered to $30^{\circ} \mathrm{C}$ and the cells incubated for a further $4 \mathrm{~h}$ to allow transcription from the $\mathrm{T} 7$ promoter in pT7-7 constructs and the consequent synthesis of pyruvate decarboxylase. The cells were collected by centrifugation at $4500 \mathrm{~g}$ for $10 \mathrm{~min}$ at $4{ }^{\circ} \mathrm{C}$ and then lysed in buffer containing $30 \mathrm{~mm}-\mathrm{K}_{2} \mathrm{HPO}_{4}$ $2 \mathrm{mM}-\mathrm{MgCl}_{2}, 0 \cdot 1 \%$ Nonidet P-40, $10 \mathrm{~mm}$-2-mercaptoethanol, $0 \cdot 1 \mathrm{~mm}$ ThDP, $0 \cdot 15 \mathrm{mg}$ lysozyme $\mathrm{ml}^{-1}$ and $2 \mu \mathrm{g}$ DNAase $\mathrm{I} \mathrm{ml}^{-1}$. Lysates were centrifuged to remove cell debris, and then assayed for PDC activity or denatured at $95^{\circ} \mathrm{C}$ for $3 \mathrm{~min}$ in cracking buffer $(60 \mathrm{mM}$-Tris $/ \mathrm{HCl}$, $\mathrm{pH} 6.8,1 \%, \mathrm{v} / \mathrm{v}, 2$-mercaptoethanol, $10 \%, \mathrm{v} / \mathrm{v}$, glycerol, $0.01 \%$ bromophenol blue). Proteins were separated by $12.5 \%(\mathrm{w} / \mathrm{v})$ SDSPAGE. Each lane contained $50 \mu \mathrm{g}$ protein as determined using a Bicinchoninic Acid Protein Assay Kit (Sigma). Bands were visualized with Coomassie brilliant blue $\mathrm{R} 250$.

$D N A$ sequencing. The sequence of the modified PDC gene, after insertion of the synthetic oligonucleotides, was confirmed by cloning appropriate restriction fragments into $\mathrm{M} 13 \mathrm{mpl} / \mathrm{mpl} / 9$ and sequencing using a T7 DNA Polymerase Sequencing Kit (Pharmacia-LKB).

Production of anti-yeast PDC antibodies. Antibodies against PDC were raised by injecting rabbits with $500 \mu \mathrm{g}$ of a commercial preparation (Sigma) in complete Freund's adjuvant, followed by further injections of $250 \mu \mathrm{g}$ enzyme in incomplete adjuvant every 4-6 weeks until reasonable titres were obtained. Serum was used without further purification for Western blot analyses

Western blot analysis. Whole-cell extracts were separated by SDSPAGE as above, then electroblotted onto nitrocellulose membranes using the carbonate buffer system described by Dunn (1986). Any remaining protein binding sites on the membranes were blocked with Tris-buffered saline-(TBS) Tween buffer $(150 \mathrm{~mm}-\mathrm{NaCl}, 10 \mathrm{~mm}$ Tris $/ \mathrm{HCl}, 0.1 \%$ Tween $20, \mathrm{pH} 7 \cdot 4$ ) containing $0.25 \%$ gelatin. After three $5 \mathrm{~min}$ washes in TBS-Tween, the filters were incubated for $2 \mathrm{~h}$ in rabbit anti-yeast PDC antiserum diluted 1:1000 in TBS-Tween containing $0.25 \%$ gelatin. The membranes were washed three times in TBS-Tween followed by a $\mathrm{I} \mathrm{h}$ incubation in horseradish-peroxidaselinked goat anti-rabbit antibody diluted $1: 1000$ in TBS-Tween containing $5 \%(\mathrm{w} / \mathrm{v})$ skimmed milk powder. After several brief washes in TBS-Tween, the filters were incubated in ECL chemiluminescent detection reagent for $1 \mathrm{~min}$, drained, covered in plasticwrap, and exposed to Fuji RX100 film for 2 min at room temperature.

Determination of enzyme activity. PDC activity was determined in the soluble fraction of the $E$. coli lysates using $5 \mathrm{~mm}$-pyruvate, $5 \mathrm{~mm}$ $\mathrm{MgCl}_{2}, 0 \cdot 1 \mathrm{mM}$-ThDP, 10 units alcohol dehydrogenase $\mathrm{ml}^{-1}, 0.15 \mathrm{mM}-$ $\mathrm{NADH}$, in $50 \mathrm{mM}$-MES buffer ( $\mathrm{pH} \mathrm{6.5)}$ by measuring the conversion of $\mathrm{NADH}$ to $\mathrm{NAD}^{+}$at $340 \mathrm{~nm}$. One unit of activity is defined as the amount of activity required for the conversion of $1 \mu \mathrm{mol}$ of NADH to $\mathrm{NAD}^{+}$per min. This assay system does not distinguish PDC from lactate dehydrogenase. The observed activity was, therefore, corrected for controls performed in an identical manner but omitting alcohol dehydrogenase.

\section{Results and Discussion}

\section{Construction of a yeast PDC expression system}

The yeast $p d c l$ gene was initially cloned into the multiple cloning site vector pUC18 as a $4.2 \mathrm{~kb}$ HindIII fragment from YEp13-PDC1 which, although under lac promoter control, resulted in low levels of recombinant protein

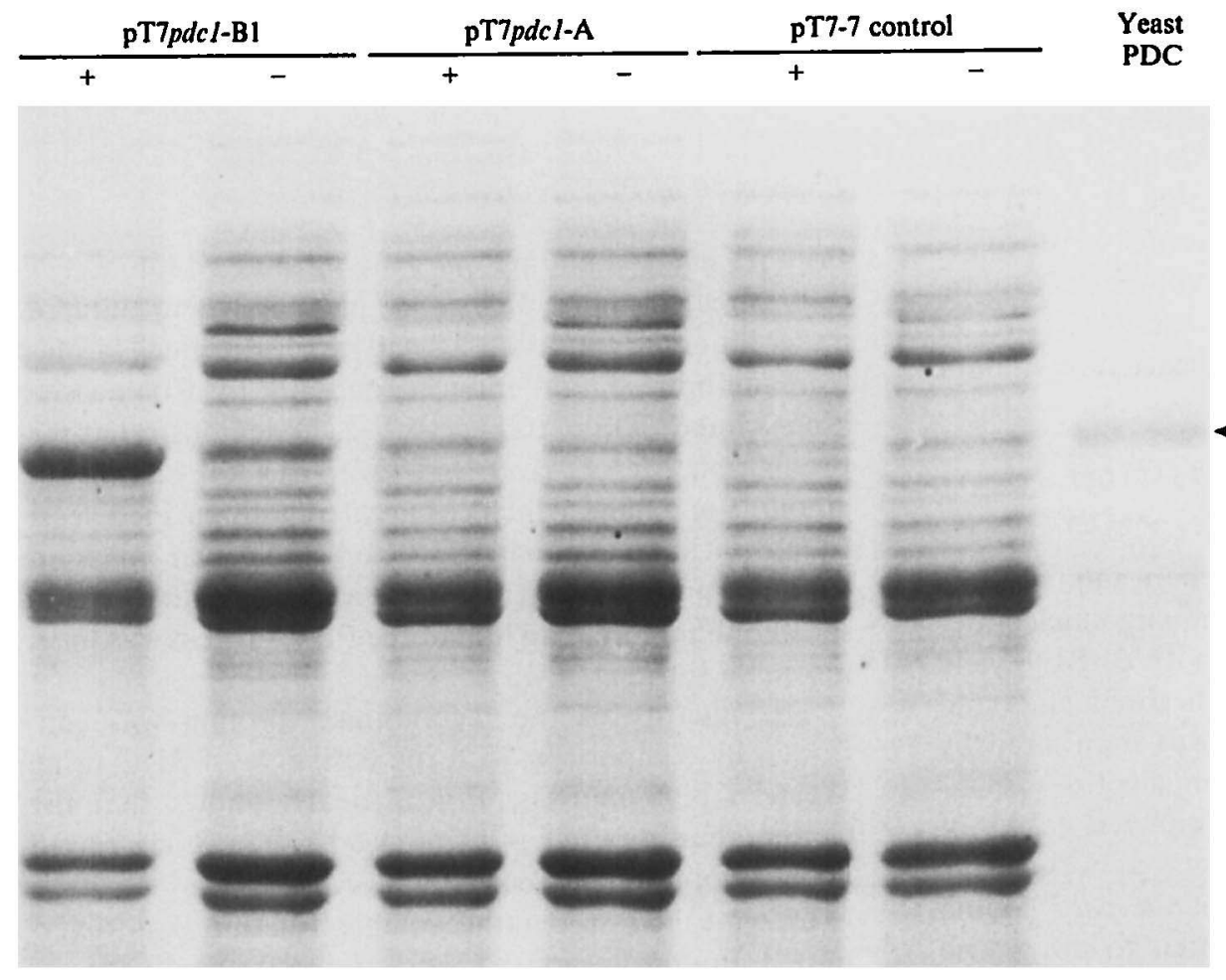

Fig. 2. Expression of the cloned yeast $p d c$ I gene in $E$. coli. Crude extracts from uninduced $\left(30^{\circ} \mathrm{C}\right)(-)$ and induced $\left(42^{\circ} \mathrm{C}\right)(+)$ cells containing the plasmids pT7pdcl-B1, pT7pdcl-A or the control pT7-7 were displayed on SDS-polyacrylamide gels and stained with Coomassie blue as described in Methods. The arrowhead shows the position of PDC. Partially purified yeast PDC was purchased from Sigma and included as a standard. Only the relevant portion of the gel (corresponding to a molecular mass range of approximately $30-100 \mathrm{kDa}$ ) is shown. 


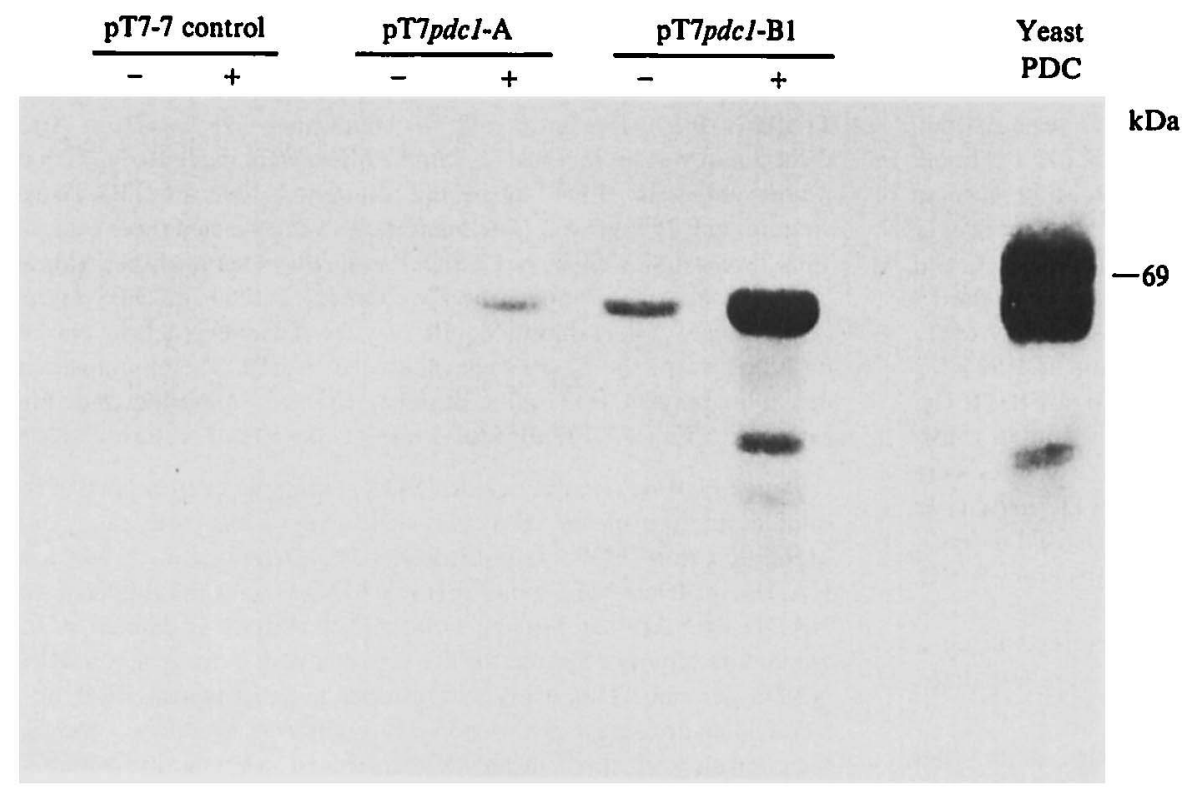

Fig. 3. Western blot analysis of yeast PDC expressed in $E$. coli. Lane designations are as for Fig. 2. The upper band of the doublet in the yeast PDC standard track appears to be due to a contaminant in the commercial preparation. expression. The same fragment was then cloned into the plasmid p T7-7 (Tabor \& Richardson, 1985) which placed it under the control of the strong T7 $\phi 10$ promoter (pT7pdcl-A, Fig. 1), but again protein expression was poor. This low level of expression was thought to be the result of the distance of the $p d c l$ initiation codon from the $\mathrm{T} 7$ promoter and the absence of an adjacent ribosome-binding sequence, since $1.2 \mathrm{~kb}$ of non-coding sequence separated the gene from the promoter in this construction. We then sought to improve expression by constructing a plasmid in which the upstream noncoding sequence was removed, and the $p d c l$ gene was placed at the $\phi 10$ translational start, within 9 bases of the $\phi 10$ ribosome-binding sequence. The $\phi 10$ initiation codon is contained within an NdeI site (CA/TATG), allowing coding regions with an NdeI site to be positioned in frame at the start codon. As the ATG of the $p d c l$ gene was not contained within an NdeI site, an adapter was designed to create this restriction site and reform the $5^{\prime}$ end of the gene:

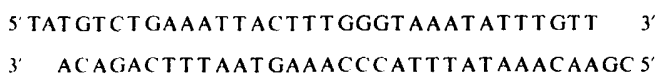

This adapter had single stranded overhangs to facilitate cloning into $\mathrm{NdeI}$ and Bst BI sites. The oligonucleotides were annealed, ligated, then digested with $B s t B I$ to yield double stranded dimers of $66 \mathrm{bp}$ with BstBI ends and an internal $N d e$ I site. This process was monitored by $(\gamma-32$ P)ATP end-labelling of the oligonucleotides.

BstBI digestion of YEp13-PDC1 removed $1.2 \mathrm{~kb}$ of non-coding region upstream of the gene as well as the first 32 nucleotides from the 5 '-end of the $p d c l$ coding region. The 66-mer adapter was ligated to the $8.4 \mathrm{~kb}$
Bst $\mathrm{B} 1$ YEp13-PDCl fragment and recircularized to form YEp8.4 (Fig. 1b). After NdeI digestion, the fragment from this plasmid was inserted into the $\mathrm{NdeI}$ site of pT7-7 to form $\mathrm{pT} 7 p d c \mathrm{l}-\mathrm{B} 2$ and the $3.2 \mathrm{~kb}$ of non-coding region $3^{\prime}$ to the gene was removed by HindIII digestion [pT7pdcl-B1, Fig. I (b)].

Restoration of the 5'-end of the pdcl gene and its positioning at the $\phi 10$ translational start site was confirmed by DNA sequencing of the XbaI/HindIII fragment from pT7pdcl-B1 (Fig. 1c). The ribosome binding site and the NdeI restriction site of the plasmid are indicated.

\section{Expression of PDC proteins in E. coli}

Both pT7pdcl-A and pT7pdc1-B1 introduced into E. coli cells directed the synthesis of protein when cultured under inducing conditions. Analysis of whole-cell lysates from uninduced and induced cultures by Coomassieblue-stained SDS-PAGE gels (Fig. 2) demonstrated the production by $E$. coli (pT7pdcl-B1) of significant amounts of a band which comigrated with purified yeast PDC, with an estimated subunit molecular mass of $62 \mathrm{kDa}$. A comparison of soluble and insoluble fractions showed that more than half of the PDC protein was in an insoluble form.

The identity of the recombinant protein was confirmed by comparison with the native yeast PDC using Western blot analysis. Fig. 3 clearly shows that the cloned gene product is recognized by antibody raised against commercial yeast PDC.

Enzyme activity in the soluble fraction was determined under uninduced and induced conditions as 
Table 1. PDC activity in soluble fraction of $E$. coli lysates from cells transformed with various constructs

\begin{tabular}{lcr}
\hline \hline & \multicolumn{2}{c}{ Activity [units (g cells)-1] } \\
\cline { 2 - 3 } Construct & Uninduced & Induced \\
\hline pT7-7 & 15 & 5 \\
PT7pdc1-A & 7 & 87 \\
pT7pdc1-B1 & 45 & 249 \\
\hline \hline
\end{tabular}

described in Methods, and the results are shown in Table 1. These results suggest that the positioning of the $p d c 1$ gene directly downstream of the highly efficient ribosome-binding site enhanced its expression as suggested by Rosenberg et al. (1987) with regard to the efficiency of translation from genes expressed in this system. It is of interest that the pT7pdcl-B1 construct showed some PDC activity $(18 \%)$ even under non-inducing conditions. Presumably the $\lambda c I 857$ repressor has not blocked the $P_{L}$ promoter tightly enough to totally inhibit synthesis of the T7 RNA polymerase, resulting in a background level of PDC expression in E. coli cells containing this construction.

The $p d c l$ gene product, at the level of expression achieved here, did not appear to be detrimental to the $E$. coli host. A comparison was also made of the growth rate of $E$. coli containing either the control vector or the PDC construct under inducing conditions, in LB with and without $2 \%(w / v)$ glucose. Similar growth rates were achieved under all conditions.

Under anaerobic conditions the main competitors for pyruvate are the native $E$. coli enzymes pyruvate formate lyase and lactate dehydrogenase. The $K_{\mathrm{m}}$ for pyruvate for these two enzymes is $2.05 \mathrm{~mm}$ (Knappe et al., 1974) and $4.4 \mathrm{~mm}$ (Tarmy \& Kaplan, 1968), respectively. This is higher than the $K_{\mathrm{m}}$ for pyruvate of yeast $(1.1-1.3 \mathrm{mM}$, Boiteux \& Hess, 1970) or Zymomonas mobilis (0.91.0 mM, Thomas et al., 1990) PDC. The higher affinity of PDC for its substrate explains the results of Brau \& Sahm (1986) who found a reduction in the formation of lactate, formate and acetate with a corresponding increase in ethanol production in E. coli expressing the Z. mobilis $p d c$ gene. A similar effect on the metabolism and by-product formation in E. coli may be occurring on expression of the yeast $p d c l$ gene.

In this paper we have described an efficient expression system for the production of yeast PDC in E. coli. The results show that, whatever the origin and role of the different PDC subunits in yeast, the $p d c l$ gene alone is capable of yielding an active enzyme. We plan to investigate further the domain involved in the binding of the co-factor ThDP using site-directed mutagenesis to change specific nucleotides within a structural motif common to many ThDP-dependent enzymes (Hawkins et al., 1989). The T7 expression system described herein will enable the rapid analysis of such alterations and, hence, definition of specific amino acids essential for catalysis, eventually leading to a more complete description of structure-function relationships in this protein.

The authors are grateful to S. Tabor and S. Hohmann for the gifts of plasmids. This work was supported by the Australian Research Council, Grant no. A08830696.

\section{References}

BolteuX, A. \& Hess, B. (1970). Allosteric properties of yeast pyruvate decarboxylase. FEBS Letters 9, 293-296.

BRAU, B. \& SAHM, H. (1986). Cloning and expression of the structural gene for pyruvate decarboxylase of Zymomonas mobilis in Escherichia coli. Archives of Microbiology 144, 296-301.

DUNN, S. D. (1986). Effects of the modification of transfer buffer composition and the renaturation of proteins in gels on the recognition of proteins on Western blots by monoclonal antibodies. Analytical Biochemistry 157, 144-153.

Gounaris, A. D., Turkenkopf, I., Civerchia, L. L. \& Greenlie, J. (1975). Pyruvate decarboxylase III: specificity restrictions for thiamine pyrophosphate in the protein association step, subunit structure. Biochimica et Biophysica Acta 405, 492-499.

Hawkins, C. F., Borges, A. \& Perham, R. N. (1989). A common structural motif in thiamin pyrophosphate-binding enzymes. FEBS Letters 255, 77-82.

KNapPe, J., Blaschkowski, H. P., GröbneR, P. \& Schmitt, T. (1974). Pyruvate formate-lyase of Escherichia coli: the acetyl-enzyme intermediate. European Journal of Biochemistry 50, 253-263.

Kuo, D. J., Dikdan, G. \& Jordan, F. (1986). Resolution of brewers' yeast pyruvate decarboxylase into two isozymes. Journal of Biological Chemistry 261, 3316-3319.

Maniatis, T., Fritsch, E. F.. \& Sambrook, J. (1982). Molecular Cloning: A Laboratory Manual. Cold Spring Harbor, NY. Cold Spring Harbor Laboratory.

Rosenberg, A. H., LADE, B. N., Chui, D.-S., Lin, S.-W., Dunn, J. J. \& STUDIER, F. W. (1987). Vectors for selective expression of cloned DNAs by T7 RNA polymerase. Gene 56, 125-135.

SchmitT, H. D., Ciriacy, M. \& Zimmermann, F. K. (1983). The synthesis of yeast pyruvate decarboxylase is regulated by large variations in the messenger RNA level. Molecular and General Genetics 192, 247-252.

TABOR, S. \& RiChARDSON, C. C. (1985). A bacteriophage T7 RNA polymerase/promoter system for controlled exclusive expression of specific genes. Proceedings of the National Academy of Sciences of the United States of America 82, 1074-1078.

TARMY, E. M. \& KaPlan, N. A. (1968). Kinetics of Escherichia coli $\beta-D-$ lactate dehydrogenase and evidence for pyruvate-controlled change in conformation. Journal of Biological Chemistry 243, 2587-2596.

Thomas, G., Diefenbach, R. \& Duggleby, R. G. (1990). Inactivation of pyruvate decarboxylase by 3-hydroxypyruvate. Biochemical Journal 266, 305-308.

ZeHender, H. \& UllRiCh, J. (1985). Amino acid composition of $\alpha$ - and $\beta$-chains of yeast and wheat germ pyruvate decarboxylase. FEBS Letters 180, 51-54. 